\title{
Processos de Subjetivação em Arte e Saúde Mental em um Manicômio Judiciário
}

\author{
Antônio Vladimir Félix-Silva ${ }^{1}$ \\ ${ }^{1}$ Universidade Federal do Piauí, PI, Brasil.
}

\author{
Gabriela Pinheiro Soares ${ }^{2}$ \\ ${ }^{2}$ Fundação Gregório Baremblitt, MG, Brasil.
}

\begin{abstract}
Resumo: Este artigo é um recorte de uma pesquisa-intervenção realizada em um Hospital de Custódia e Tratamento Psiquiátrico (HCTP). Por meio da cartografia, como método e modo de fazer pesquisa qualitativa em psicologia, e da utilização de objetos relacionais da arte em rodas de conversa, tenda do conto e círculos de cultura para a produção dos dados com "pacientes", agentes penitenciários e técnicos, objetivou-se: a) cartografar processos de subjetivação em arte e saúde mental de pacientes no cotidiano do HCTP; b) mapear a produção de subjetividades custodiadas e seus efeitos nos modos de subjetivação de pacientes; c) analisar modos de sujeição e resistência frente à produção de subjetividades custodiadas. A análise cartográfica dos dados mostra que há, nos processos de subjetivação dos "pacientes": a) problematização dos modos de sujeição às instituições que agenciam a produção de subjetividades custodiadas, principalmente do poder médico que decide quem está, ou não, apto para a vida em "liberdade"; b) modos de resistência à produção de subjetividades custodiadas, principalmente à excessiva medicalização e às grandes limitações na produção em saúde que atingem o HCTP. As conclusões apontam a arte como dispositivo, principalmente, e a poesia como objeto relacional com o fora da clausura para anunciar que o HCTP é visto pelos "pacientes", pelos agentes penitenciários e (passa a ser visto) também pelos cartógrafos como prisão, manicômio judiciário, e não como hospital; sendo cada participante da pesquisa não apenas um preso que utiliza psicotrópicos, mas também sujeito que pode devir autor para testemunhar o fracasso/sucesso da psiquiatrização da loucura.
\end{abstract}

Palavras-chave: Saúde Mental, Subjetividades Custodiadas, Manicômio Judiciário, Arte.

\section{Subjectivation Processes in Art and Mental Health in a Judiciary Asylum}

Abstract: This article is part of a broader intervention research conducted at a Custody and Psychiatric Treatment Hospital (HCTP). This study aimed to (a) map the processes of subjectivation in art and mental health in the daily life of patients of the HCTP; (b) to map the production of incarcerated subjectivities and its effects on subjectivation modes; and (c) to analyze subjection and resistance modes as a result of the production of incarcerated subjectivities. Data was collected using cartography and relational art objects in conversation circles and tale tents, based on the narratives of "patients", correctional officers and technicians of the custody unit. According to the cartographic analysis, patients problematize the subjection modes of the institutions responsible for producing their incarcerated subjectivities, especially in regard to the medical power that gets to decide who is apt for life in "freedom". Patients also showed resistance towards producing incarcerated subjectivities, mainly considering the excessive medicalization and major limitations in the healthcare provided by HCTP. The results indicate that "patients", penitentiary agents, and even cartographers perceive the HCTP as a prison (Judicial Asylum) rather than as a hospital. Each participant is not only a prisoner who use psychotropic drugs, but also a subject capable of testifying the failure/success of the psychiatrization of madness.

Keywords: Mental Health, Custodied Subjectivities, Judiciary Asylum, Art. 


\title{
Procesos de Subjetivación en el Arte y Salud Mental en un Manicomio Judicial
}

\begin{abstract}
Resumen: Este artículo es parte de una investigación-acción realizada en el Hospital de Custodia y Tratamiento Psiquiátrico (HCTP). Por medio de la cartografía como método y modo de hacer investigación cualitativa en psicología, y de la utilización de objetos relacionales del arte en ruedas de conversación, tienda del cuento y círculos de narrativas de la cultura para la producción de datos con "pacientes", agentes penitenciarios y técnicos del HCTP, se tuvo por objetivo: a) cartografiar los procesos de subjetivación en el arte y en la salud mental de pacientes en el cotidiano del HCTP; b) trazar la producción de subjetividades custodiadas y sus efectos en los modos de subjetivación de pacientes; c) analizar modos de sujeción y resistencia frente a la producción de subjetividades custodiadas. El análisis de la cartografía revela que existe en los procesos de subjetivación de los "pacientes": a) problemática de los modos de sujeción a las instituciones que gerencian la producción de subjetividades custodiadas, sobre todo el poder médico que decide quién está apto o no para vivir en "libertad"; b) formas de resistencia a la producción de subjetividades custodiadas, especialmente la medicalización excesiva y las grandes limitaciones a la producción en salud que afecta el HCTP. Las conclusiones apuntan al arte como dispositivo, principalmente la poesía como objeto relacional con el fuera de la clausura para anunciar que el HCTP es visto por los "pacientes", por los agentes penitenciarios y pasa a ser visto también por los cartógrafos como una prisión, un manicomio judicial, pero no como un hospital, siendo cada participante de la investigación no solo un detenido que utiliza psicotrópicos, sino también un sujeto que puede devenir autor para testimoniar el fracaso/éxito de la psiquiatrización de la locura.
\end{abstract}

Palabras clave: Salud mental, Subjetividades Custodiadas, Manicômio Judicial, Arte.

\section{Introdução}

Neste artigo, apresentamos caminhos e efeitos de uma cartografia dos processos de subjetivação em arte e saúde mental a partir do relato de uma pesquisa-intervenção realizada em um Hospital de Custódia e Tratamento Psiquiátrico, denominado Unidade Psiquiátrica de Custódia e Tratamento (UPCT), no qual pacientes presos de diversas cidades cumprem medida de segurança; não somente o "louco infrator" - sujeito considerado inimputável no momento em que entrara em conflito com a lei, incapaz de entender que estava cometendo uma infração, conforme o Decreto-Lei no 7.209 de 11 de Julho de 1984 do Código Penal Brasileiro (Ibrahim \& Vilhena, 2014; Santos, Farias, \& Pinto, 2015), - mas também presos que acabam se tornando pacientes.

Trata-se de presos que se tornam pacientes a partir de internações compulsórias no HCTP por insuficiência de dispositivos e de recursos extra-hospitalares na Rede de Atenção Psicossocial (Raps), tais como tratamento ambulatorial com prescrição terapêutica e atenção psicossocial, residências terapêuticas, centros de atenção psicossocial (Caps) III e Álcool e Drogas (AD) III. Neste contexto, a internação compulsória de semi-imputáveis inclui aplicação de medida de segurança a pessoas usuárias de substâncias ilícitas e é determinada com fins de tratamento psiquiátrico após "evidências" de "risco de violência" contra si mesmo ou contra a família, antes ou após a prisão, geralmente, por pequenos furtos e roubos, em delegacias de polícia, cadeias públicas, penitenciárias ou presídios. A internação compulsória preventiva é a medida de segurança aplicada com a finalidade de evitar que o sujeito inimputável volte a infringir as normas, haja vista a "potencialidade para praticar ações lesivas" contra a sociedade por ser considerado incapaz de responder por seus atos (Ministério Público Federal, 2011; Santana, Pereira, \& Alves, 2017; Santos \& Farias, 2014).

Além disso, há casos de substituição da pena de prisão por medida de segurança, com transferências conquistadas de presídios por meio de acordos ou ações que envolvem pagamento de advogados por pais 
e mães das camadas médias ou abastadas. Há também as mães, em geral mulheres negras das camadas populares menos favorecidas, que abrem mão de tudo o que têm, acreditando que o filho, usuário de drogas consideradas ilícitas, irá receber tratamento no HCTP e conquistará a liberdade após dois anos cumprindo medida de segurança, considerando que não apresentaria periculosidade para a sociedade por não ser "louco" ou "doido", como se referiam, muitas vezes, os participantes da pesquisa a quaisquer usuários de substâncias psicoativas. Em todo caso, trata-se, como ressalta Jacobina (citado por Ministério Público Federal, 2011, p. 65), "da condenação penal a uma sanção, sob o disfarce de uma 'sanção terapêutica'”.

O HCTP fica localizado numa região metropolitana. Apesar de a instituição ser conhecida como "Hospital de Custódia", os participantes da pesquisa não se enunciam como pacientes, mas como presos; anunciam o estabelecimento não como hospital, mas como "prisão", "fábrica de loucos", "oficina do diabo", “inferno", "custódia sem 'S' de Saúde” e "Unidade Psiquiátrica de Custódia e Acabamento". Esses enunciados e enunciações corroboram um dos nossos objetivos, a saber: mapear a produção de subjetividades custodiadas e seus efeitos nos modos de subjetivação dos pacientes. Nesta introdução e ao longo do texto, destacamos as linhas de força que compõem o agenciamento dessa produção de subjetividade por meio da articulação dos equipamentos da sociedade de controle: psiquiatria, família, justiça, medicina, direito, política, economia, manicômio etc.

Como mostraremos, a análise desses processos de subjetivação denuncia a redução epistemológica dos sujeitos com sofrimento psicológico à criminalização da loucura e à medicalização do confinamento. Por meio da "medicalização geral da existência", "psicologizam-se logo as coisas" e psiquiatrizam-se todos para que entrem "na sociedade da norma, da saúde, da medicina, da normalização" (Foucault, 1994/2010, p. 160).

Também nomeado de "hospital-prisão" (Santos \& Farias, 2014), quaisquer que sejam os nomes dados ao HPCT e "quaisquer que tenham sido, ao longo dos anos, os nomes que tenha tido [a UPCT], . . é ainda do manicômio que estamos falando aqui" (Polack \& Sivadon, 2013, p. 13). Presos, familiares, agentes penitenciários, gestores, juízes, promotores, advogados, técnicos, psicólogas, psicólogos, psiquiatras, pesquisadores, todas e todos ainda "carregamos em nós o manicômio". Ele continua nos protegendo não só dos crimes inenarráveis (Roudinesco, 2008), mas também da "loucura da história" (Polack \& Sivadon, 2013, p. 13), das interdições do corpo e dos crimes não ditos da sociedade de controle e do medo, pois "cada cultura tem a loucura que merece" (Foucault, 1994/2002, p. 164). Diante desse sofrimento ético-político (Sawaia, 2008), nos perguntamos: como se configuram os processos de subjetivação em arte e saúde mental de pacientes presos em um contexto de produção de subjetividades custodiadas?

Para pensar tal problemática, neste artigo, optamos pela escrita testemunha das vozes que ouvimos e que narramos aqui como uma forma de mostrar a fragmentação das subjetividades custodiadas e o fracasso do tratamento psiquiátrico, que corresponde ao sucesso do sistema prisional (Foucault, 1994/2002). A partir de uma perspectiva ético-estético-política e da aposta em um grupo dispositivo (Barros, 2007) constituído por 18 pacientes presos que ainda nos fazem ver, falar e escrever sobre um cenário de práticas eminentemente marcado pela ausência de psicólogas(os), esperamos contribuir para a atuação profissional no âmbito da psicologia.

Nesta perspectiva, a cartografia dos processos de subjetivação em arte e saúde mental provocou a produção de processos de desinstitucionalização de pacientes presos, a quem a justiça havia concedido a desinternação condicional, mas se mantinham internados por insuficiência dos dispositivos mencionados anteriormente. Também a pacientes que foram desinternados durante a pesquisa por meio das intervenções que realizamos junto à Secretaria de Estado da Justiça e da Cidadania (Sejuc) e à Coordenação Estadual de Saúde Mental, ao núcleo familiar ou à família extensiva, além de outros processos criativos na perspectiva da clínica antimanicomial e da utopia da transformação radical dos saberes psi e da prática psiquiátrica (Guattari, citado por Amarante, 2003). Trata-se de desdobramentos da cartografia como modo de fazer pesquisa-intervenção que tinha como objetivos: a) cartografar processos de subjetivação em arte e saúde mental de pacientes no cotidiano do HCTP; b) mapear a produção de subjetividades custodiadas e seus efeitos nos modos de subjetivação de pacientes; c) analisar modos de sujeição e resistência frente à produção de subjetividades custodiadas.

A produção de subjetividades custodiadas - efeito do agenciamento de processos de semiotização e enunciação do louco, da loucura, do crime e do castigo - 
constitui-se de múltiplas entradas e múltiplas saídas da vida em cena nos territórios de existência. As múltiplas saídas produzidas com a cartografia e mapeadas durante a pesquisa se referem à: invenção de objetos relacionais da arte (poesia, letras e composição de músicas); cogestão dos encontros, corroborando intervenções para localização de familiares e visitas às famílias até restabelecimento de vínculos; acesso a serviços de saúde; redução de danos causados pela prescrição de uso excessivo de psicotrópicos para usuários de substâncias ilícitas recém-internados; consulta pública junto ao Conselho Nacional de Justiça (CNJ) para dar ciência de decisão judicial, processos em andamento e agendamento de exames junto ao Instituto Técnico-Científico de Perícia (Itep). Nessa produção, mediada pelas interações intersubjetivas e semióticas, operam a articulação de dispositivos jurídicos, psiquiátricos, sociais, econômicos, educacionais e políticos, gerando a coexistência de uma multiplicidade de processos de subjetivação, ora segmentados, ora singulares (Guattari \& Rolnik, 2010).

Para a problematização dessa produção de subjetividades custodiadas, pensamos, inicialmente, com Foucault e outros autores que, no nosso ponto de vista, corroboram direta ou indiretamente com a caixa de ferramentas-conceitos denominada esquizoanálise (Deleuze \& Guattari, 1980/2012; Pelbart, 2013; Perrone, 2009).

A esquizoanálise contribuiu para nosso trabalho com arte e saúde mental e contribui também para a produção desta escrita testemunha à medida que trata de produzir inconsciente sensível e maquínico "politicamente, economicamente, historicamente", entendendo "por produção de inconsciente [sensível]. . . a mesma coisa que produção de desejo num campo social histórico ou a apropriação de enunciados e enunciações de um gênero novo" (Deleuze, 2006, p. 345). Neste sentido, a análise dos processos de subjetivação inclui, em alguma medida, a análise dessa produção e desses enunciados e enunciações que compõem uma complexa rede tecida pelas linhas de força da vida: linha dura molar e linhas de fuga maleável e molecular (Deleuze \& Guattari, 1980/2012; Rolnik, 2006), mostrando como essas linhas vão alinhavando e desalinhavando modos de vida; bem como elas se convertem ora em forças assujeitadas ao poder sobre a vida, ora em forças da vida (Pelbart, 2013).

Por meio da arquegenealogia da loucura (Foucault, 1961/2009, 1994/2010, 2001/2010), Foucault
(1994/2002) mostrou que houve um deslocamento das representações sobre o tema na literatura, na pintura e no teatro - a partir da internação pela família, entre os séculos XVII e XVIII - para o enquadramento como doença mental e anormalidade, no início do século XIX. Assim, a loucura foi socialmente excluída e o louco considerado "a pessoa a ser excluída de todos os domínios": da sociedade comum, do trabalho, da família, dos discursos e dos jogos (p. 261). Por razões econômicas e sociais, a associação da loucura à doença mental transformou os estabelecimentos de internação em hospitais psiquiátricos, e os loucos passaram a ser "considerados pacientes cujos distúrbios tinham causas que se referiam ao carácter ou de natureza psicológica . . . Desde então, os distúrbios mentais tornaram-se o objeto da medicina e uma categoria social chamada psiquiatria nascera" (Foucault, 1994/2002, p. 266).

$\mathrm{Na}$ contemporaneidade, as modulações da produção de subjetividades capitalísticas e a máquina psiquiátrica (Deleuze \& Guattari, 1985; Guattari \& Rolnik, 2010) vêm produzindo subjetividades que criam no imaginário da sociedade de controle (Deleuze, 2008), de consumo e do medo (Bauman, 2008), manicômios mentais nos quais confinamos nossa desrazão (Pelbart, 2009). Esse complexo agenciamento contribui para a reprodução do estigma sofrido por quem vive sujeito a tratamento psiquiátrico em regime de custódia, sendo esse assujeitamento duplamente marcado pelo delito que cometeu em situação de grave sofrimento psíquico e pelas "doenças transmitidas por psiquiatria, com psiquiatria, em psiquiatria”, como escreveu Luiz Nunes Brasil durante o processo de desativação do Engenho de Dentro (Citado por Oliveira, 2009, p. 27).

No Brasil, antes da criação dos manicômios, o louco era considerado vadio e quando praticava alguma desordem poderia ser internado em Santas Casas de Misericórdia ou enclausurado em cadeias públicas ou presídios, sendo, muitas vezes, isolado em cárcere privado pela família (Arbex, 2013; Santos \& Farias, 2014). O início da assistência psiquiátrica às pessoas consideradas loucas começou a acontecer na segunda metade do século XIX (Correia, Lima, \& Alves, 2007), e o primeiro Manicômio Judiciário foi fundado, em 1921, no Rio de Janeiro, recebendo o nome de Hospital de Custódia e Tratamento Psiquiátrico Heitor Carrilho (HCTPHH), somente a partir do novo código penal. Esse manicômio "foi alvo explícito 
de fechamento das vagas, após a desinternação jurídica de todos os pacientes", sendo extinto em março de 2013 (Santos \& Farias, 2014, p. 516). Máquina terrível foi o Manicômio de Barbacena (MG), conhecido mundialmente como "holocausto brasileiro" pelas violências institucionais praticadas e pelo genocídio de 60 mil pessoas entre 1930 e 1980 (Arbex, 2013).

No contexto atual, o manicômio judiciário, tal qual a prisão, faz parte da loucura do "capitalismo vídeo-financeiro contemporâneo" (Batista, 2017, p. 23) e da "pornografia penal", cujo manejo da lei pelos novos jogos de saber e pelo uso arbitrário de poder inclui a espetacularização da criminalidade e a exibição midiática da ordem para ampliação do número de presídios sob o pretexto de garantir segurança pública (Wacquant, 2007).

À diferença de uma penitenciária, cujas celas estão marcadas pela superlotação e os espaços dentro e fora dos muros são marcados por rebeliões e domínio de facções rivais e pela lei do mais forte, no manicômio judiciário em que realizamos a pesquisa, as celas têm de um a três pacientes, denominados presos ou custodiados, a considerar o modo como eles se anunciam e se reconhecem e como a gestão e os agentes penitenciários a eles se referem.

O manicômio judiciário em questão está geograficamente situado entre os presídios masculino e feminino, faz parte de um complexo penitenciário do Estado e tem em comum com a maioria das prisões não só do Brasil, mas também dos Estados Unidos e da França, de acordo com a obra de Loïc Wacquant (2007), o "tratamento desumano e degradante" (p. 452), marcado por "insalubridade, deterioração das instalações, promiscuidade atingindo o paroxismo, higiene catastrófica, grave carência de pessoal" (p. 451).

O Estado brasileiro reconhece que os pacientes presos estão excluídos da atenção psicossocial de base comunitária, na perspectiva da Lei n. 10.216/2001. Prova disso é a tentativa de compensação por meio da implementação das diretrizes do Parecer sobre Medidas de Segurança e Hospitais de Custódia e Tratamento Psiquiátrico sob a Perspectiva da Lei n. 10.216/2001 (Ministério Público Federal, 2011) e da Política Nacional de Atenção Integral à Saúde das Pessoas Privadas de Liberdade no Sistema Prisional (PNAISP) (Ministério da Saúde, 2014), além de outras Políticas antimanicomiais interministeriais que preveem a substituição dos Manicômios Judiciários existentes por ações intersetoriais sinali- zadas pela resolução n. 113, de 20 de abril de 2010, do Conselho Nacional de Justiça e pela resolução n. 4, de 30 de julho de 2010, do Conselho Nacional de Política Criminal e Penitenciária, e pelas Portarias n. 94/2014, n. 95/2014 e Portaria n. 001/2014, que institui a PNAISP nos dispositivos do Sistema Único de Saúde (SUS) (Correia et al., 2007; Ministério da Saúde, 2014; Prado \& Schindler, 2017; Santos \& Farias, 2014; Santos et al., 2015).

Esses processos instituintes de construção de políticas fazem parte dos resultados da luta antimanicomial. Foi a partir do encontro entre protagonistas do Movimento Popular em Saúde, que emergiu entre o final dos anos 1950 e início dos anos 1960, e do Movimento dos Trabalhadores em Saúde Mental, no final dos anos 1970, centrais no movimento da Reforma Sanitária na década de 1980 (Tenório, 2002), que se inicia a Reforma Psiquiátrica Brasileira. Inspirada na transformação da psiquiatria na Itália, proposta por Basaglia (2010), e na experiência de Guattari (2012), na França, ela se configura um processo sócio-histórico que tem buscado a atenção psicossocial de base comunitária às pessoas com sofrimento psíquico, por meio da Política Nacional de Saúde Mental (Lei no 10.2016/2001), da Raps e dos serviços substitutivos ao hospital psiquiátrico, tais como os Caps, os Serviços Residenciais Terapêuticos e o programa "De Volta para Casa" (que pode ou poderia propiciar às pessoas o retorno ao convívio familiar e social), os Centros de Convivência e os Pontos de Cultura (Amarante, 2007).

Não deixamos de reconhecer as dificuldades encontradas para a desinternação de pacientes presos e para a execução dos processos de desinstitucionalização relacionados ao HCTP, principalmente no manicômio judiciário no qual realizamos a pesquisa; considerando, sobretudo, que só havia uma residência terapêutica em funcionamento na cidade, apesar da notícia de recursos orçados para outras duas, que ao final não foram abertas durante o período da pesquisa.

Outra dificuldade encontrada já apontada em outros estudos (Prado \& Schindler, 2017; Soares Filho \& Bueno, 2016) diz respeito à execução da medida de segurança nos moldes da internação compulsória em manicômio judiciário. Não obstante, destacamos, a partir de revisão de literatura, as experiências realizadas por meio do Programa de Atenção Integral ao Paciente Judiciário (PAI-PJ), em Minas Gerais, desde 1999, e do Programa de Atenção Integral ao Louco 
Infrator (Paili) ${ }^{1}$, em Goiás, iniciado em 2009. As ações desses programas substituem a internação compulsória judicial por acompanhamento ao longo do processo criminal, oferecendo tratamento ambulatorial e atenção integral e intersetorial da rede que compõe o SUS e o Sistema Único de Assistência Social (Suas) à pessoa com transtornos mentais que entra em conflito com a Lei (Correia et al., 2007; Prado \& Schindler, 2017; Santos et al., 2015; Soares Filho \& Bueno, 2016), principalmente por meio dos dispositivos da Raps.

\section{Percursos metodológicos}

Historicamente, as relações entre arte e loucura e arte e saúde mental têm afetado a produção das subjetividades em diferentes contextos, contribuindo para modificar, ao longo do tempo, as narrativas discursivas e os enunciados acerca da loucura. No Brasil, o trabalho realizado por Nise da Silveira foi um marco no que se refere ao assunto.

Nise da Silveira introduziu, na década de 1940, o trabalho com arte e artefatos produzidos por pacientes como ferramentas de arteterapia no Centro Psiquiátrico do Rio de Janeiro, mais conhecido como Engenho de Dentro (Santos, 1994). Dessa forma, possibilitou que, ainda hoje, possamos experimentar sensações ao conhecer obras de arte e biografias de artistas como Arthur Bispo do Rosário (Dantas, 2009).

Atualmente, na perspectiva da saúde mental, o trabalho com arte, - no âmbito da Raps - vem ganhando espaço e proporcionando melhorias para a atuação profissional e para familiares e pessoas com sofrimento psíquico.

Esta cartografia, como modo de fazer pesquisa-intervenção (Barros \& Kastrup, 2010) no manicômio judiciário, implicou a composição de paisagens psicossociais com os participantes por meio de ferramentas da arte relacional (Dias, 2004; Rolnik, 2006) e do uso de metodologias participativas, também denominadas práticas integrativas grupais, tais como rodas de conversa, círculos de cultura, tenda do conto, esquizodrama e teatro do oprimido. $\mathrm{O}$ uso de objetos relacionais da arte vincula-se à interação e ao intercâmbio para a produção de conhecimentos com os participantes da pesquisa, e à concepção de arte contemporânea: arte como experimentação (Rolnik, 2002), a exemplo dos parangolés e instalações de obras da arte conceitual de Hélio Oiticica (Aguilar, 2016) e da experimentação de objetos relacionais da arte inspirada no uso dos objetos relacionais de Lygia Clark (Rolnik, 1998).

Objetos relacionais são artefatos da arte que produzem afecções: "blocos de sensações compostos pelas práticas estéticas aquém do oral, do escritural, do gestual, do postural, do plástico... que têm como função desmanchar as significações coladas às percepções triviais e as opiniões impregnando os sentimentos comuns" (Guattari, 2012, p. 104). Nesta cartografia, tais afecções mobilizaram os participantes da pesquisa não só para que produzissem seus próprios objetos relacionais, mas também para agir como grupo-sujeito que se fez ver e falar sobre os modos de afetar e deixar-se afetar pela arte e pela produção de conhecimentos sobre subjetividades custodiadas.

Não obstante, o trabalho com arte não se deu na perspectiva da arteterapia nem da arte educação, mas na perspectiva ético-estético-política da cartografia como modo de fazer pesquisa-intervenção. Para a produção dos dados, ou seja, o acompanhamento dos processos de subjetivação e mapeamento da produção de subjetividades custodiadas, realizamos 25 encontros com 18 participantes da pesquisa, mediados por objetos relacionais da arte: curtas-metragens, documentários, filmes (apostando que o cinema vai ao manicômio, levávamos equipamento multimídia), músicas, clipes, fotografias (tomando emprestado e emprestando o olhar do fora de dentro do manicômio judiciário); tatuagens (a maioria produzida no sistema prisional); modelagens; maquetes do "Hospital de Custódia" - tomando como referência a exibição de um vídeo que mostra a instalação de Penetráveis de Hélio Oiticica (Duarte, 2008); cartas (muitas cartas intercambiadas entre familiares), diários de afecções (nomeados por alguns de diário de um detento); raps, contos e poesias (produzidos pelos participantes) e esquizodrama (a partir de cartografias do corpo em cenas produzidas pelos participantes).

Além disso, realizamos seis rodas de conversas com nove dos 16 agentes penitenciários que trabalham em trios por plantão de $24 \mathrm{~h}$; três rodas de conversa com um psiquiatra que presta serviço de $4 \mathrm{~h}$ uma vez por semana; três enfermeiros e duas técnicas de enfer-

${ }^{1}$ Acerca da metodologia de funcionamento do PAI-PJ e do Paili, ver: Correia et al., 2007; Prado \& Schindler, 2017; Santos et al., 2015; Soares Filho \& Bueno, 2016. 
magem, que prestam serviços por dia de $8 \mathrm{~h}$, alternadamente; e duas assistentes sociais, que também prestam serviço de $8 \mathrm{~h}$ uma vez por semana. Realizamos doze reuniões com a gestão, diretoria e vice-diretoria. Ao todo, foram 70 entradas e saídas.

Para efetivar as intervenções desse modo de fazer pesquisa, realizamos rodas de conversa com agentes penitenciários, assistentes sociais, gestores, enfermeiros e técnicos de enfermagem, além de encaminhamentos junto a profissionais da assistência jurídica e dos direitos humanos de fora do manicômio judiciário, coordenador estadual de saúde mental e promotor. Também participamos de audiência pública na Assembleia Legislativa do Estado, reunião organizada pelo Centro de Apoio Operacional às Promotorias de Justiça de Defesa da Cidadania (CAO Cidadania), com vistas à efetivação e efetivo cumprimento do Plano Operativo Estadual para Atenção Integral à Saúde da População Prisional (POE Saúde Prisional). Nas audiências e reuniões, os pacientes presos não passavam de números citados pela coordenação de saúde mental ou pela direção da UPCT.

\section{Rompendo grades e produzindo fissuras nos muros do manicômio}

No manicômio judiciário, os pacientes presos se encontram, literalmente, na encruzilhada de caminhos entre a criminologia e a psiquiatria (Rauter, 2003). Nesse limbo, as referências técnicas para atuação ético-política de psicólogas(os), mesmo na perspectiva dos direitos humanos e da luta contra as práticas de privação de liberdade e enclausuramento de pacientes com transtornos mentais, não deixam de constituir um paradoxo, haja vista a coexistência do trabalho nas Comissões Técnicas de Classificação (CTC)/Exame Criminológico ${ }^{2}$ e a aposta na "reflexão crítica com vistas ao fim dos Hospitais de Custódia e Tratamento Psiquiátrico, mais conhecidos por Manicômios Judiciários" (Conselho Federal de Psicologia, 2012, p. 24).

No contexto do HCTP no qual realizamos a pesquisa, o universo de 66 pacientes judiciários, entre 43 internos e 23 em tratamento ambulatorial, do sexo masculino; faixa etária entre 18 e mais de 60 anos, sendo 32 deles da região metropolitana e 34 de outros municípios do Estado, conforme dados estatísticos do Sistema Integrado de Informações Penitenciárias (InfoPen)
(Ministério da Justiça, 2012). A maioria dos considerados pela justiça como inimputáveis é caracterizada pela psiquiatria no âmbito das psicoses e a minoria no campo das toxicomanias e dos transtornos de personalidade antissocial. Quando iniciamos a pesquisa, constatamos, em uma das rodas de conversa realizadas com a gestão, que havia 29 presos cumprindo medida de segurança; sete que haviam feito a conversão da pena para medida de segurança; outros nove estavam na denominada situação temporária de internação; e o mais paradoxal: havia seis que deveriam estar em liberdade, alguns por terem cumprido a medida de segurança e recebido parecer de periculosidade cessada, fornecido por peritos do Itep, e outros por terem medida de segurança extinta por meio de sentença de desinternação, também nomeada de "desinternação condicionada", conforme consulta pública de processos judiciais junto ao CNJ. Esses dados foram confirmados por Débora Diniz (2013) quando da publicação do livro A custódia e o tratamento psiquiátrico no Brasil.

Dos 43 pacientes presos, 18 participaram diretamente da pesquisa e dos encontros mediados por artefatos da arte relacional; 20 não recebiam visitas de familiares, visitas de conhecidos nem de desconhecidos e somente três tinham direito à visita íntima. Dentre esses que recebiam visita íntima encontrava-se um usuário de substâncias ilícitas cujo pai fazia de tudo para subornar o sistema, de modo que ele permanecesse custodiado - não obstante, o pai nunca o visitava para saber como se dava o tratamento psiquiátrico.

Dito isso, apresentamos a seguir um recorte do acompanhamento dos processos de subjetivação cartografados e passamos a usar trechos de nossos diários cartográficos, tais como registrados; às vezes, para que nos distanciássemos do espaço-tempo da pesquisa - uma maneira que encontramos de fazer a sistematização e análise de implicação, aproximando leitora e leitor do manicômio judiciário e do sofrimento ético-político que testemunhamos.

As grades externas e internas das instituições da violência e de aprisionamentos da saúde mental se abrem e se fecham. Os cartógrafos entram e saem, adentrando as entranhas de um manicômio judiciário. Eles escolhem a experimentação dessa experiência como modo de fazer pesquisa-intervenção,

\footnotetext{
${ }^{2}$ Sobre análise de discurso nas narrativas que marcam os laudos e as práticas do Exame para Verificação da Periculosidade (EVCP) dos considerados inimputáveis, ver a obra de Cristina Rauter (2003): Criminologia e subjetividade no Brasil.
} 
permanecendo, uma vez por semana, durante duas horas, com 18 pacientes custodiados, numa sala na qual realizam a cartografia dos processos de subjetivação em arte e saúde mental desses pacientes presos por um período de um ano e oito meses, constantemente observados por dois ou três agentes penitenciários. Nas mãos, diários cartográficos para registros das afecções do corpo e uma potente caixa de afecções com ferramentas-conceitos da esquizoanálise e de autores pós-estruturalistas. Nos modos de produzir as informações no campo de intervenção, uma perspectiva ético-estético-política (Barros, 2007), o olhar vibrátil (Rolnik, 2006) e o desejo de mundo sem aprisionamentos, desejo como força ativa e como vontade de potência (Deleuze, 2006), para que as subjetividades de pesquisador e participantes não sejam totalmente capturadas pelo desejo de manicômio (Pelbart, 2009) (Diário cartográfico do autor).

'Você nunca sabe quando eles vão surtar. Eles podem surtar a qualquer momento' (Agente penitenciário $\mathrm{X})^{3}$, reflete em voz alta, reproduzindo uma lógica manicomial, o agente penitenciário $\mathrm{X}$, com a intenção de que os cartógrafos ouçam vozes, na primeira vez que visitam as celas-quartos dos pacientes custodiados, no terceiro mês de pesquisa. Os cartógrafos caminham entre os corredores das celas escuras. Sentem as picadas de mosquitos. Aspiram o mau cheiro da fossa - estourada há mais de dois meses e por muitos meses depois - e do esgoto a céu aberto. Sentem ânsia de vômitos; sentem medo da dengue e da tuberculose ${ }^{4}$. Eles sentem calor. Ouvem gritos, gritos e mais gritos: ' $\mathrm{Eu}$ quero ir pra Jericó! Eu quero ir pra Jericó! Eu quero ir pra Jericó!' (Curió) $)^{5}$ 'Agente! Agente! Agente! Tou com dor de dente' (Manon). 'Agente! Agente! Agente! Tá faltando água' (Juriti). 'Agente! Hoje tem psicologia?' (Graúna, referindo-se às atividades da pesquisa). 'Água, aqui, quando tem, é liberada só três vezes por dia, durante 15 minutos' (Agente $\mathrm{Z}$, Diário cartográfico do autor).
No início, as vozes dos agentes alertam para que os cartógrafos se cuidem porque os presos podem enlouquecer a qualquer momento. Seis meses depois, as mesmas vozes, expressando um agenciamento médico-psiquiátrico e sujeição à lógica manicomial, chamam a atenção dos cartógrafos, novamente, para que se cuidem, se não enlouquecerão ou serão acometidos pela fadiga de compaixão (Lago \& Codo, 2010), como o agente Z. Este e outros trabalhadores entram permanentemente em crise e são reconhecidos pelos sucessivos afastamentos por depressão e pelos efeitos da medicalização do trabalho e da vida no manicômio judiciário. $\mathrm{O}$ Agente $\mathrm{Z}$ faz parte da minoria que tece linhas maleáveis do desejo, mesmo que essas linhas se tornem praticamente invisíveis na engrenagem de linhas duras do sistema.

Aqui, era para funcionar como modelo. O respeito está na relação entre nós [agentes] e eles [presos], não na opressão. Os presos sabem que, aqui, eu sou agente e eles são diferentes. Minha farda está ali, eu só a uso quando há uma ocorrência. Ser um sujeito pensante em um meio que lhe é estranho e hostil ao seu trabalho é como estar enxugando gelo (Agente Z).

Os processos de subjetivação dos cartógrafos vão sendo cada vez mais afetados pelos modos de resistência à produção de subjetividades custodiadas. Ante as batidas de grades e os gritos de sobrevidas que desejam afetos, água e outros modos de cuidado e atenção à saúde, a escuta dos cartógrafos não fica surda (Baptista, 1999). Eles têm alucinações auditivas. Escutam o tempo todo a pergunta: "Qual saúde bastaria para libertar a vida em toda parte onde esteja aprisionada pelo homem e no homem, pelos organismos e gêneros e no interior deles?" (Deleuze, 2011, p. 14). As imagens que lhes chegam são de gritos - temática da série La edad de la ira (Guayasamín, 1985); - gritos de vida. Eles seguem apostando que "é a vida que serve de ponto de apoio último para novas lutas e reivindicações coletivas" (Pelbart, 2011, p. 13).

\footnotetext{
${ }^{3}$ As letras do alfabeto, utilizadas aqui no lugar dos nomes dos agentes penitenciários, não correspondem às iniciais do nome próprio de nenhum deles.

${ }^{4}$ Em janeiro de 2013, identificamos um participante da pesquisa com sintomas de tuberculose que estava infectado. No mesmo período, o sistema de vigilância em saúde do Estado realizou, às pressas, o teste rápido e diagnosticou outros pacientes custodiados e 13 agentes penitenciários com nível de bacilos no sangue um pouco acima do aceitável pela vigilância sanitária.

${ }^{5}$ Os nomes dos presos foram substituídos por nomes de pássaros, adotando-se pseudônimos conforme expresso no TCLE anexado ao projeto de pesquisa, cadastrado no Portal Brasil e aprovado pelo Comitê de Ética em Pesquisa (CAAE 02830412.5.0000.5296).
} 
É hora da medicalização do confinamento. É a primeira vez que os cartógrafos acompanham esse ritual. Agentes penitenciários, técnicos de enfermagem e cartógrafos, três vezes "presos" - a contar o número de portões que os separam da rua. Presos para acompanhar presos: preso que se benze três vezes, antes de ingerir os psicotrópicos e beber um copo d'água; preso que benze o corpo e os fármacos que toma e que vem tornando corpo-morto o que ainda lhe resta de vida em seu corpo vivo. - 'Você tem código de doido!' Afirma um paciente preso que se recusa a tomar a medicação se ela for dada por esse agente penitenciário. Depois, o agente fala aos cartógrafos: 'Já fui à junta psiquiátrica. $\mathrm{O}$ preso sabe, ele me viu na consulta. Não vou discutir com ele' (Diário cartográfico do autor).

'Dra. [H], o hospital é só aqui dentro [sala de psiquiatria], daqui para fora, quando a senhora vai embora, os agentes fazem o que querem com os presos' (Rouxinol).

'Aqui, quem não entra doido sai doido. Quem entra doido sai mais doido ainda!' (Sanhaço).

'Hoje, está toda uma maquiagem porque o secretário vem fazer uma visita' (Tangará).

A análise desses processos de subjetivação, ou seja, desses modos de sentir, de pensar e de se expressar por meio dessa língua que pede passagem (Rolnik, 2006) nos faz afirmar que os pacientes presos protestam, falam que já passaram pelo manicômio judiciário representantes da Vigilância Sanitária, da Ordem dos Advogados do Brasil, da Coordenação Estadual de Saúde Mental, do Conselho Estadual dos Direitos Humanos, do Centro de Referência em Direitos Humanos, do Centro de Apoio Operacional às Promotorias de Justiça de Defesa da Cidadania e do Plano Operativo Estadual para Atenção Integral à Saúde da População Prisional, já passaram Promotores, Juízes, Secretários e vários gestores já estiveram à frente do manicômio judiciário e "nada mudou. Entra ano e sai ano, e tudo continua como está. Não muda. Nada!" (Socó).

Ao contrário da cegueira da justiça e do saber da instituição psiquiátrica, que operam molarmente em nome da produção de subjetividades custodiadas, os cartógrafos não estão nus. Tal como preconiza o Conselho Federal de Psicologia (2012), por meio da cartilha Referências técnicas para atuação das (os) psicólogas (os) no Sistema Prisional, seus olhos não cegam diante de "uma vida nua não atribuível e não testemunhável" (Agamben, 1998/2008, p. 156) e de corpos mal-amados, abandonados pela família, pelo Estado, pela psiquiatria e pela Justiça. Corpos molambos. Farrapos cujos fiapos de vida teimam em resistir. Corpos presos ainda assim produzem resistência aos corpos títeres e à gorda saúde (Deleuze, 2008) dos corpos malhados pelas modulações do capitalismo farmacopornográfico (Preciado, citado por Pelbart, 2013).

Em cada encontro, os participantes da pesquisa apresentam seus próprios objetos relacionais da arte que, com exceção das tatuagens, foram produzidos durante a pesquisa. Na tenda do conto, as tatuagens, em geral, narram histórias de amores iniciados e interrompidos, ganhos e perdas na prisão. No esquizodrama, os raps contam recaídas pelo uso de substâncias psicoativas, entradas em conflito com a lei e volta ao sistema prisional. Nas rodas de conversa, os cadernos de liberdade contam e cantam o amor e os sonhos de viver em liberdade: uma vida... (Deleuze, citado por Agamben, 2000).

Nos encontros nos quais o cinema vai ao manicômio, o diário de afecções de um detento fala dos modos de viver custodiado em criança, na adolescência e na vida adulta: uma vida no sistema prisional. O livro memorial de um dos pacientes presos narra artimanhas do sofrimento psíquico, atravessamentos e agenciamentos molares das instituições de controle em arranjos familiares e contextos sociais que lhe envolvem em situação de abandono, adoção, perdas e ganhos, escolarização, alcoolismo, amizades, realizações e frustrações amorosas, trabalho e subempregos, desemprego, luta permanente e fracassada pelo reconhecimento da família de origem, crises depressivas, busca desesperada por atenção em unidades de saúde e falta de acesso aos dispositivos de assistência social e da rede de atenção psicossocial, além da falta de recursos para adquirir remédios; nomadismo urbano, diurno e noturno; surto alcoólico, crime e castigo. Agenciamentos que resultaram em dessubjetivação.

Além dos modos de assujeitamento, os processos de subjetivação em arte e saúde mental também apontam para uma experiência do fora (Levy, 2011), modos de resistência à produção de subjetividades 
custodiadas, situando-se entre modos de reinventar-se uma liberdade e as cartografias do corpo torturado psicologicamente e fisicamente:

Quando eu fui preso, antes de vir para cá, os agentes penitenciários me colocaram no seguro; a cela onde ficam os presos mais perigosos: homicidas, ladrões, estupradores. Veio um dos agentes e me tirou da cela e um preso trouxe uma garrafa de café fervendo e jogou em cima de mim. Eu subi numa cadeira de rodas e fiquei pulando de dor. Eu gritava. Os agentes ficam só olhando de braços cruzados. Depois, os agentes soltaram os presos; eles me espancaram e me amarram: os pés e as mãos junto às grades. Além de me amarrar, me deram choques, aqui, as marcas [mostra o corpo marcado pela queimadura e pelos choques]. Eu pensei que ia morrer. Eu gritava. Os agentes ficavam só olhando de braços cruzados. Então, os presos passaram um fio no meu pescoço e eu fiquei um minuto, um minuto e meio mais ou menos, sem fôlego. Tiraram o fio do meu pescoço e depois me deram mais choques. Eu gritava. Os agentes ficavam só olhando de braços cruzados (Pintassilgo).

O Estado que prende para ressocializar ou mantém em custódia para tratar acaba violando os direitos humanos, ou seja, o Estado agencia a produção de subjetividades custodiadas. Pintassilgo tinha vindo passar o carnaval na cidade e em crise de abstinência, ousou roubar o celular da filha de uma autoridade. No que se refere ao modo de vida do paciente preso, dependendo dos atravessamentos de classe, gênero, raça e etnia, muitas vezes, ainda impera o poder de deixar sobreviver à vida nua (Agamben, 1998/2008), privado de liberdade para deixar morrer privado de vida. A vida nua é a vida matável, que pode deixar morrer ou ser exterminada sem que se configure crime ou sacrifício (Rosa, 2007). Também por isso, no manicômio judiciário, tanto as possibilidades quanto as dificuldades de um paciente preso devir escrita como testemunha falam de um sofrimento ético-político mediado pelas injustiças sociais (Sawaia, 2008).

Na Unidade Psiquiátrica de Custódia e Tratamento/Não recebemos muito mais do que um acabamento/ As assistentes sociais parecem que não servem quase para nadal Parece até que à assistência social está completamente abandonadal
De manhã, se tem pão não tem café;/ Se tem café, não tem pão./ Assim eles nos levam na mais pura ilusão./ Quando aparecem pessoas sensíveis/ Que gostam de ajudar/ Eles fazem todo o possivel pra essa ajuda acabar/ Aqui, a gente ri pra não chorar/ É onde o anjo mal diz amém/ É o único lugar que o doentel É obrigado a dizer que está bem!/ Prefiro estar num presídio/ Porque lá sei onde estou/Aqui, quiseram fazer um hospital/ Mas foi nisto que se transformou./ Enfermeiro finge que trabalhal $O$ psicólogo vem só passar o tempo/ Estou cansado de estar num meio de tanto fingimento./ Será que com tanto esforço/ Correndo assim atrás do vento/ Eles vão conseguir darl O tão esperado tratamento? (Sabiá)

As testemunhas traçam uma série de violações de direito à vida; violações acometidas como ecos do estado de exceção que marca o espaço político contemporâneo (Agamben, 1998/2008), linhas molares e duras da produção de subjetividades capitalísticas e sua necropolítica do desejo de fazer morrer e deixar morrer (Mbembe, 2018) por ser pobre e por ser negro, por ser considerado louco e criminoso.

"Eles dizem que é hospital, clínica, só porque tem remédios?" (Mandarim). "Vocês [cartógrafos] estão confundindo. Vocês estão achando que aqui é um hospital, mas aqui não é hospital não, é prisão" (Pardal, na primeira roda de conversa). "Aqui, a gente só tem grade e psicotrópicos" (Falcão). "É a nossa realidade, um inferno, um inferno, um inferno..." (Cisne). Os versos e prosas mostram que os pacientes presos não estão privados só da liberdade de ir e vir, mas também de assistência social, ou seja, do direito à educação, à assistência jurídica e à atenção à saúde. Alguns com decisão judicial de desinternação condicional há mais de três anos permaneciam nas celas e no manicômio. Outros eram tratados como presos perigosos até durante o percurso que vai da UPCT à Residência Assistida de um hospital psiquiátrico, consequência da pesquisa-intervenção.

Ao realizarmos consulta pública de processos junto ao CNJ, nos surpreendíamos com decisões judiciais, nas quais constava, por exemplo: "Trata-se de medida de segurança imposta a [Fulano de Tal dos Anjos], em que the foi concedida a desinternação condicional em 14/07/2009 (fls. 59/60). Todavia, o inimputável continua internado na UPCT por não existir interesse da família em recebê-lo (fls. 64/65)". A maioria dos pacientes pre- 
sos que se encontrava nessa situação não tinha conhecimento do teor das decisões judiciais; apenas um deles, que passava a maior parte do tempo capinando o pátio interno da UPCT, permanecia lá por "vontade própria", dada a cronificação do processo de institucionalização produzida por anos de internação.

Depois de nossas intervenções junto à Sejur e de esta acionar a Promotoria de Direitos Humanos e a direção de um grande hospital psiquiátrico, o qual tem uma área em que funciona uma residência assistida, às vezes, o mesmo juiz que havia expedido a decisão ou outro dava nova ordem e estabelecia prazo para liberação do paciente preso sob pena da direção do estabelecimento ser acusada de mantê-lo em situação manicomial.

"Eu vou fugir para onde, se eu não tenho para onde ir?" (Íbis). Íbis se envolveu com parente de juiz. Então, ele sabe como a instituição Justiça pesa na produção de subjetividades custodiadas. Como Íbis, com exames de que cessou a periculosidade ou de que cumpriu a medida de segurança, existiam, no mínimo, mais cinco pacientes presos, a considerar Ave-Severina, que morreu em 2012, no Hospital do Câncer; dois que foram transferidos para a residência assistida de um hospital psiquiátrico, em 2012; e mais dois que estavam, há mais de um ano, presos desinternados, um deles, raramente, muito raramente, frequentava um Caps $\mathrm{AD}$. Eles poderiam estar em casa ou vivendo numa residência terapêutica. $O$ pássaro Ave-Severina ficou mais de 30 anos preso, ora engaiolado, ora fazendo trabalho de capinagem. Ele morreu com câncer nos ossos depois de uma vida e uma morte, literalmente, severinas, no sentido de sujeição e servidão maquínica ao capitalismo manicomial.

Hoje, acompanhamos a decisão do juiz ameaçando à gestão da UPCT de que se o sistema mantiver qualquer um dos desinternados preso será considerado cárcere privado. . Hoje, registramos a convocação da promotoria exigindo providências ao coordenador de saúde mental do Estado que ainda não conhece o manicômio judiciário. ... Hoje, acompanhamos a visita da coordenação de saúde mental e registramos a expedição de mandado judicial, pelo juiz, para que o diretor do Hospital Psiquiátrico cumpra a ordem e aceite a transferência de dois pacientes presos para a Residência Assistida - inicialmente, o diretor havia negado... . Hoje, acompanhamos a transfe- rência de Patativa que saiu com sua televisão nas costas até a viatura, mas teve de ir algemado em uma posição que lhe impedia de ver a cidade [um ano depois de morar na residência assistida, ele ganhou um terreno da avó numa cidade da região metropolitana, construiu sua casa e mudou-se]. ... Hoje, visitamos Mandarim durante sua internação para realização de uma cirurgia; ontem, ele passou à noite batendo grades com dor [era pedra na vesícula]; . . durante outra a visita, após a cirurgia, pedimos ao agente penitenciário que retirasse as algemas pelo menos enquanto ele tomava a sopa. ... Acompanhamos um dos desinternados, durante o percurso que vai do manicômio judiciário até o hospital psiquiátrico, e nos mantivemos informados acerca do estado dele e dos outros quatro que articulamos a volta para casa (Diários cartográficos dos autores).

Portanto, os cartógrafos produziram algumas linhas de fuga nas grades e muros do manicômio judiciário. A pesquisa-intervenção desassossegou as instituições que agenciam a produção de subjetividades custodiadas.

"Aqui está ficando como uma cadeia qualquer. Eles [presos] não querem se comportar como bandidos perigosos? Então, serão tratados como bandidos e não como doentes" (Agente X). Um ano depois de iniciada a pesquisa-intervenção, $o$ agente penitenciário $X$ volta a ser a voz da razão, alertando aos cartógrafos para que eles fiquem atentos, pois são muitos presos usuários de drogas, eles são mais perigosos que "os doidos" e podem estar armando planos de sequestro e fuga.

"As vozes vêm e vão/ As vozes vão e vêm/ Ainda vêm e vão, as vozes... As vozes vão e vêm/ As vozes vêm e vãol Agora, eu sei. Elas vêm e elas vão... Eu sou só. Eu sei que sou só. A voz é passageira, é um antes e um agora. .." (Andorinha). Andorinha, no início da pesquisa, vinha, aos primeiros encontros, totalmente dopado de psicotrópicos. Durante uma das rodas de conversa em que o psiquiatra estava presente, conseguimos convencê-lo a diminuir a medicação dele. Então, o pássaro começou a criar asas ao participar dos encontros, até que chegou o dia de voar e voltou a morar com a família.

Ao perceber que os pacientes presos estão substituindo o excesso de remédios, efeito da medicalização do confinamento, pela possibilidade de bons encontros com paixões alegres e afecções do corpo que geram arte como potência de ação (Spinoza, 
1677/2011), as vozes de alguns agentes penitenciários ecoam molarmente aprisionadas pela trama da instituição da violência (Basaglia, 2010). Esses processos de subjetivação segmentados pela sujeição servil ecoam no lugar do suposto saber, anunciando a intenção de dificultar os encontros entre os cartógrafos e os pacientes presos.

Com medo de que os cartógrafos façam denúncia da situação que presenciaram no hospital, em que o paciente cirurgiado tomava sopa algemado, em um dia como hoje, o Agente Penitenciário K assedia moralmente os cartógrafos diante da gestão do manicômio judiciário que, cabisbaixa, escuta surda e permanece muda. $\mathrm{K}$ fala que os cartógrafos podem ser doutores em psicologia, mas ele é doutor na mente dos presos. Sabe que os presos só pensam em fugir e que o trabalho dele e dos outros agentes penitenciários é evitar a fuga. $\mathrm{K}$ duvida da intencionalidade do trabalho dos cartógrafos, pergunta se eles não estão afetados pela síndrome de Estocolmo.

$\mathrm{O}$ "Dr. K" não sabe que o trabalho dos cartógrafos não é promover a fuga dos presos nem contribuir com a repressão militarizada de quem pode fugir ou sabe fazer fugir. $\mathrm{O}$ trabalho da cartografia é produzir encontros e mapear as afecções do corpo, acompanhado os processos de subjetivação tanto de quem não sabe como de quem sabe fazer fugir, seja dentro ou fora dos muros da prisão, incluindo os cartógrafos. "Fazer do fora um território no espaço, . . . desterritorializar o inimigo através da ruptura interna de seu território, desterritorializar-se a si mesmo renunciando, indo a outra parte. . Uma outra justiça, um outro movimento, um outro espaço-tempo" (Deleuze \& Guattari, 1980/2012, p. 14)

O Agente Penitenciário X também se considera "doutor em educação no sistema prisional", capaz de dar aula para novos agentes e até para professores com os quais ele fez sua capacitação no início da carreira. Durante uma roda de conversa, o "Dr. X" se pergunta: "Por que os direitos humanos só reivindicam direitos para bandidos?". Também pergunta por que nós, cartógrafos, só realizamos esse trabalho de psicologia com os pacientes presos. Em seguida, fala de seu sofrimento psicológico e do sofrimento de sua esposa que está deprimida e ninguém faz nada.

O esquecimento como força reativa não deixa o último agente $\mathrm{X}$ ver, tal qual o último homem (Nietzsche, 1883/2011), como ele, os cartógrafos e sua esposa não estão privados da liberdade de ir e vir. Também não têm cerceado o direito de acesso às políticas públicas de saúde, ao atendimento nas unidades básicas e no Caps, mesmo que para a efetivação desses direitos tenhamos que negociar e disputar espaços de poder na rede de relações como tal o poder se estabelece e se desestabiliza, e a rede de relações se restabelece (Foucault, 1999/2010), na maioria das vezes, lutando para superar os problemas do SUS. Ao final dessa roda de conversa, fornecemos os contatos de um CAPS III e o telefone de uma assistente social.

\section{Considerações finais: afecções do corpo dos cartógrafos}

Neste estudo, tratamos de responder como se configuram os processos de subjetivação em arte e saúde mental de pacientes presos no contexto de produção de subjetividades custodiadas. Mapeamos essa produção de subjetividades custodiadas e analisamos seus efeitos nos modos de subjetivação dos pacientes presos. Assim, concluímos que os processos de subjetivação segmentados produzem modos de sujeição e reproduzem lógicas manicomiais, coexistindo com processos de subjetivação singulares que produzem resistência à produção de subjetividades custodiadas. Assim, a resistência se dá como uma tradução dos modos de narrar e dos modos de escrever em prosa e em versos, que apontam para a necessidade de uma escrita de si e para a problematização de uma estética da existência em um dos contextos da sociedade contemporânea: o manicômio judiciário.

Mostramos que o trabalho com objetos da arte relacional põe os presos em contato virtual com o fora (Levy, 2011) e a cidade, via imagens, poesias, músicas, fotografias e cartas, possibilitando, às vezes, o contato deles com outras pessoas, advogados, promotores e juízes, coordenadores de saúde mental, conselheiros e representantes dos direitos humanos. Também põem alguns presos em contato com familiares que os tinham deixado no esquecimento, com o corpo adoecendo da frágil saúde produzida pela medicalização do confinamento no manicômio judiciário.

Os processos de subjetivação em saúde mental são traduções de palavras tecidas por meio da cartografia de narrativas em prosa e em versos, linhas de fuga maleáveis, tais como as que tecem a rede que possibilita transferências do manicômio judiciário para a residência assistida ou para casa, e linhas moleculares do desejo, tais como as forças que possibilitam devir autor e experimentar um fora (desterritorialização do mani- 
cômio judiciário). Escritas de si em versões de violações de direitos e de defesa do direito à vida que lhes resta, agenciamentos de enunciação e produção de subjetividades custodiadas que coexistem com processos de singularização: simulacro de liberdade em instituição total (Goffman, 2013). Versos de enunciados que são outros discursos e prosas que são dessa e de outras instituições manicomiais. Fragmentos de prosa e poesias escritas por meio de cartografias do corpo no manicômio judiciário: versos do que resta da arte da palavra grávida de palavras de liberdade: "Eu passo o tempo todo, dia e noite, pensando em liberdade. Vinte e quatro horas planejando, esperando, querendo caminhar nesse caminho da liberdade para sempre" (Sabiá); "Sou um barco à derival A navegar no marl Em busca da liberdade" (Pintassilgo).

"A palavra poética é aquela que se situa, de cada vez, na posição de resto, e pode, dessa maneira, dar testemunho. Os poetas - as testemunhas - fundam a língua como o que resta, o que sobrevive em ato à possibilidade - ou à impossibilidade de falar" (Agamben, 1998/2008, p. 160). Poemas escondidos entre a sola dos pés e o chinelo. Versos em ritmo dos passos e da tensão. Percussão silenciosa das batidas do coração. Música de um corpo cuja voz de quem ouve vozes custodiadas não pode ser e pode não ser silenciada. Afecções de um corpo-som que libera vibrações e líquidos: sua com medo de ser duplamente preso, durante a revista que se dá entre os corredores que vão da saída da cela escura à sala de encontro com os cartógrafos.

"Vivendo entre aspas" (Sabiá). Este é o verso que se inscreve no corpo do autor afetado pelo encontro com objetos relacionais da arte. Ele escreve experimentando o efeito das sensações produzidas pelas afecções do corpo com os versos de Negro Forro, poema de Adão Ventura (2001), lido pelos cartógrafos:
"Minha carta de alforria/ não me deu fazendas,/ nem dinheiro no banco, nem bigodes retorcidos./ Minha carta de alforria/ costurou meus passos/ aos corredores da noite/ de minha pele".

"O direito à vida, ao corpo, à saúde, à felicidade, à satisfação de todas as necessidades, é a réplica política aos novos procedimentos de poder" (Pelbart, 2011, p. 59). Não obstante, as forças que resistem ao poder que investe contra a vida se apoiam na própria vida, pois "as lutas não se fazem mais em nome dos antigos direitos, mas em nome da vida, suas necessidades fundamentais, a realização de suas virtualidades etc." (Foucault, citado por Pelbart, 2011, p. 59).

O manicômio judiciário é uma "fábrica de loucos", na qual um usuário de substâncias ilícitas entra e é tratado como louco e sai - quando sai - para continuar sendo tratado como "doido"; é também uma "oficina do diabo", na qual, o "doido" entra e sai - quando sai - tratado como louco e como usuário de drogas licitamente recomendadas.

As vozes que ouvimos e as afecções do corpo que testemunhamos e experimentamos no cotidiano do manicômio judiciário poderiam não fazer parte do narrável, à medida que os autores dessa multiplicidade de vozes estão sendo "despojados de todo estatuto político e reduzidos integralmente à vida nua" (Agamben, 1998, citado por Gagnebin, 2008, p. 9). Não obstante, no manicômio judiciário, tal como ressalta Agamben (2008) acerca do campo de concentração de Auschwitz, "uma das razões que podem impelir" um paciente preso "a sobreviver consiste em tornar-se uma testemunha" (Agamben, 1998/2008, p. 24), podendo devir escrita em prosa ou em versos, unicamente para testemunhar, sem, necessariamente, tornar-se um escritor, após cumprir a medida de segurança e ganhar a liberdade.

\section{Referências}

Agamben, G. (2000). A imanência absoluta. In E. Alliz (Org.), Deleuze: Uma vida filosófica (pp. 169192). Editora 34.

Agamben, G. (2008). O que resta de Auschwitz: O arquivo e a testemunha (Homo Sacer III). Boitempo. (Trabalho original publicado em 1998)

Aguilar, G. (2016). Hélio Oiticica: A asa branca do êxtase: arte brasileira de 1964 - 1980. Anfiteatro.

Amarante, P. D. C. (2003). A (clínica) e a reforma psiquiátrica. In M. Scliar, \& P. D. C. Amarante (Coords.), Archivos de saúde mental e atenção psicossocial (pp. 4565). NAU.

Amarante, P. D. C. (2007). Saúde mental e atenção psicossocial. Fiocruz.

Arbex, D. (2013). Holocausto brasileiro (3a ed). Geração Editorial.

Baptista, L. A. S. (1999). A cidade dos sábios. Sammus. 
Psicologia: Ciência e Profissão 2021 v. 41 (n.spe 4), e212322,1-16.

Barros, L. P., \& Kastrup, V. (2010). Cartografar é acompanhar processos. In E. Passos, V. Kastrup, \& L. Escóssia (Org.), Pistas do método da cartografia: Pesquisa-intervenção e produção de subjetividade. (pp. 5275). Sulina.

Barros, R. B. (2007). Grupo: A afirmação de um simulacro. Sulina.

Basaglia, F. (2010). Escritos selecionados em saúde mental e reforma psiquiátrica. Garamond.

Batista, V. M. (2017). Um grande livro sobre a pequena prisão. In I. Mendes, A pequena prisão (pp. 2328). N-1 Edições.

Bauman, Z. (2008). A sociedade individualizada: Vidas contadas e histórias vividas. Zahar. (Trabalho original publicado em 2001)

Conselho Federal de Psicologia. (2012). Referências técnicas para atuação das(os) psicólogas(os) no sistema prisional. https://bit.ly/3rndlEJ

Correia, L. C., Lima, I. M. S. O., \& Alves, V. S. (2007). Direitos das pessoas com transtorno mental autoras de delitos. Cadernos de Saúde Pública, 23(9), 19952002. http:// dx.doi.org/10.1590/S0102-311X2007000900002

Dantas, M. (2009). Arthur Bispo do Rosário: A poética do delírio. Editora Unesp.

Deleuze, G. (2006). Cinco proposições sobre a psicanálise. In L. B. L. Orlandi (Org.). A ilha deserta e outros textos (pp. 345352). Iluminuras. (Trabalho original publicado em 1953)

Deleuze, G. (2008). Conversações. Editora 34. (Trabalho original publicado em 1977)

Deleuze, G. (2011). Crítica e clínica (2a ed). Editora 34. (Trabalho original publicado em 1993)

Deleuze, G., \& Guattari, F. (1985). El anti Edipo: Capitalismo y esquizofrenia. Editorial Paidós. (Trabalho original publicado em 1972)

Deleuze, G., \& Guattari, F. (2012). Mil platôs: Capitalismo e esquizofrenia 2, vol. 5 (2a ed). Editorial 34. (trabalho original publicado em 1980)

Dias, R. (2004). A vida como vontade criadora: Por uma visão trágica da existência. In T. M. G. Fonseca, \& S. Engelman (Org.), Corpo, arte e clínica (pp. 131146). Editora da UFRGS.

Diniz, D. (2013). A custódia e o tratamento psiquiátrico no Brasil: Censo 2011. Livres/Editora UnB. https:// bit.ly/3xnUQCn

Duarte, P. S. (2008). Arte brasileira contemporânea: Um prelúdio. Silvia Roester Edições de Arte.

Foucault, M. (2002). Problematização do sujeito: Psicologia, psiquiatria e psicanálise. Ditos \& Escritos I (2a ed.). Forense Universitária. (Trabalho original publicado em 1994)

Foucault, M. (2009). História da loucura: Na idade clássica (8a ed.) Perspectiva. (Trabalho original publicado em 1961)

Foucault, M. (2010). Repensar a política. Ditos \& Escritos VI. Forense Universitária. (Trabalho original publicado em 1994)

Foucault, M. (2010). Aula de 15 de janeiro de 1975. In M. Foucault, Os anormais (pp. 2746). Martins Fontes. (Trabalho original publicado em 2001)

Foucault, M. (2010). História da sexualidade, 1: A vontade de saber. Graal. (Trabalho original publicado em 1999)

Gagnebin, J. M. (2008). Apresentação. In G. Agamben, O que resta de Auschwitz: O arquivo e a testemunha (Homo Sacer III) (pp. 917). Boitempo.

Goffman, E. (2013). Manicômios, prisões e conventos. 8a ed. Perspectiva.

Guattari, F. (2012). Caosmose: Um novo paradigma estético. Editora 34.

Guattari, F., \& Rolnik, S. (2010). Micropolítica: Cartografia do desejo. 10a ed. Vozes.

Guayasamín, O. (1985). El Grito [Pintura]. Casa-Museu Guayasamin, Quito, Equador.

Ibrahim, E., \& Vilhena, J. (2014). Manicômio judiciário: É possível ao louco-criminoso resistir? Psicologia: Ciência e Profissão, 34(4), 879893. http://dx.doi.org/10.1590/\%201982-370001542013

Lago, K., \& Codo, W. (2010). Fadiga por compaixão: O sofrimento dos profissionais de saúde. Vozes.

Lei no 10.216, de 6 de abril de 2001. (2001, 9 de abril). Dispõe sobre a proteção e os direitos das pessoas portadoras de transtornos mentais e redireciona o modelo assistencial em saúde mental. Diário Oficial da União, Seção 1. http://www.planalto.gov.br/ccivil_03/leis/leis_2001/110216.htm 
Levy, T. S. (2011). A experiência do fora: Blanchot, Foucault e Deleuze. Civilização Brasileira.

Mbembe, A. (2018). Necropolítica. N-1 Edições.

Ministério da Justiça. (2010, 30 de julho). Resolução no 4: Dispõe sobre as Diretrizes Nacionais de Atenção aos Pacientes Judiciários e Execução da Medida de Segurança. https://bit.ly/36hcig1

Ministério da Justiça. (2012). Sistema Integrado de Informações Penitenciárias - InfoPen. http://dados.mj.gov.br/ dataset/infopen-levantamento-nacional-de-informacoes-penitenciarias

Ministério da Saúde. (2014, 2 de janeiro). Portaria Interministerial no 1: Institui a Política Nacional de Atenção Integral à Saúde das Pessoas Privadas de Liberdade no Sistema Prisional (PNAISP) no âmbito do Sistema Único de Saúde (SUS). https://bit.ly/2UwfxNO

Ministério Púbico Federal. (2011). Parecer sobre medidas de segurança e hospitais de custódia e tratamento psiquiátrico sob a perspectiva da Lei n. 10.216/2001. https:/ / bit.ly/3hDsU76

Nietzsche, F. (2011). Assim falou Zaratustra. 2a ed. Companhia das Letras. (Trabalho original publicado em 1883)

Oliveira, E. (2009). Ouvindo vozes: Histórias do hospício e lendas do Encantado. Vieira \& Lent.

Pelbart, P. P. (2009). Manicômio mental: A outra face da clausura. In A. Lancetti, Saúde e Loucura 2 (4a ed., pp. 131138). Hucitec.

Pelbart, P. P. (2011). Vida capital (4a ed.). Iluminuras.

Pelbart, P. P. (2013). O avesso do niilismo: Cartografias do esgotamento. N-1 Edições.

Perrone, C. M. (2009). Esquizoanálise. In J. G. Aquino, \& S. M. Corazza. (Orgs.), Abecedário: Educação a diferença (pp. 6063). Papirus.

Polack, J-C., \& Sivadon, D. (2013). A íntima utopia: Trabalho analítico e processos psicóticos. N-1 Edições.

Prado, A. M., \& Schindler, D. (2017). A medida de segurança na contramão da Lei de Reforma Psiquiátrica: Sobre a dificuldade de garantia do direito à liberdade a pacientes judiciários. Revista Direito GV, 13(2), 628652. http:// dx.doi.org/10.1590/2317-6172201725

Rauter, C. (2003). Criminologia e subjetividade no Brasil. Revan.

Rolnik, S. (1998). Por um estado de arte: A atualidade de Lygia Clark. In Fundação Bienal de São Paulo, Núcleo histórico: Antropofagia e histórias de canibalismos, vol. 1 (pp. 456467). https://issuu.com/bienal/docs/name208154

Rolnik, S. (2002). Arte cura? Lygia Clark no limiar do contemporâneo. In G. Bertucci (Org.). Psicanálise, arte e estética de subjetivação (pp. 365-381). Imago.

Rolnik, S. (2006). Cartografia sentimental: Transformações contemporâneas do desejo. Sulina.

Rosa, S. O. (2007). Fazer viver é deixar morrer. Revista Aulas, 1(3). https://bit.ly/2V8U6ml

Roudinesco, E. (2008). A parte obscura de nós mesmos: Uma história dos perversos. Jorge Zahar.

Santana, A. F. F. A., Pereira, M. O., \& Alves, M. (2017). O (des)preparo do hospital judiciário para a ressocialização: Violação de direitos humanos. Escola Anna Nery Revista de Enfermagem, 21(3), 18. https://doi.org/10.1590/ 2177-9465-EAN-2017-0022

Santos, A. L. G., \& Farias, F. R. (2014). Criação e extinção do primeiro Manicômio Judiciário do Brasil. Revista Latinoamericana de Psicopatologia Fundamental, 17(3), 515527. http://dx.doi.org/10.1590/1415-4714.2014v17n3p515-9

Santos, A. L. G., Farias, F. R., \& Pinto, D. S. (2015). Por uma sociedade sem hospitais de custódia e tratamentopsiquiátrico. História, Ciências, Saúde - Manguinhos, 22(4), 12151230. http://dx.doi.org/10.1590/S0104-59702015000400004

Santos, L. G. P. (1994). Entrevista com Nise da Silveira. Psicologia: Ciência e Profissão, 14(13), 2227. http:// dx.doi.org/10.1590/S1414-98931994000100005

Sawaia, B. B. (2008). O sofrimento ético-político como categoria de análise da dialética exclusão/inclusão. In B. B. Sawaia (Org.), As Artimanhas da exclusão: Análise psicossocial e ética da desigualdade social (pp. 97118). Vozes.

Soares Filho, M. M., \& Bueno, P. M. M. G. (2016). Direito à saúde mental no sistema prisional: Reflexões sobre o processo de desinstitucionalização dos HCTP. Ciência \& Saúde Coletiva, 21(7), 21012110. http:// dx.doi.org/10.1590/1413-81232015217.08802016 
Spinoza, B. (2011). Ética (2a ed.). Belo Horizonte: Autêntica. (Trabalho original publicado em 1677).

Tenório, F. (2002). A reforma psiquiátrica brasileira, da década de 1980 aos dias atuais: História e conceitos. História, Ciências, Saúde - Manguinhos, 9(1), 2559. http://dx.doi.org/10.1590/S0104-59702002000100003

Ventura, A. (2001). Negro forro. In I. Moriconi (Org.), Os cem melhores poemas brasileiros do século. (p. 275). Objetiva. Wacquant, L. (2007). Punir os pobres: A nova gestão da miséria nos Estados Unidos (3a ed.). Revan.

Antônio Vladimir Félix-Silva

Professor do Programa de Pós-Graduação em Psicologia da Universidade Federal do Piauí (UFPI), Parnaíba - PI. Brasil. E-mail: wladyfelix@hotmail.com

(1) https://orcid.org/0000-0003-3084-379X

Gabriela Pinheiro Soares

Psicóloga e pós-graduanda em pela Fundação Gregório Baremblitt e Instituto Félix Guattari, Uberaba - MG. Brasil.

E-mail: gabypsoares@hotmail.com

(1) https://orcid.org/0000-0001-8697-8445

Endereço para envio de correspondência:

Avenida São Sebastião, 3950, apartamento 8, Bairro Frei Higino. CEP: 64207-005.Parnaíba -PI. Brasil.

Recebido 19/08/2018

Aceito 29/07/2019

Received 08/19/2018

Approved 07/29/2019

Recibido 19/08/2018

Aceptado 29/07/2019

Como citar: Félix-Silva, A. V., \& Soares, G. P. (2021). Processos de subjetivação em arte e saúde mental em um manicômio judiciário. Psicologia: Ciência e Profissão, 41 (n.spe 4), 1-16. https://doi.org/10.1590/1982-3703003212322

How to cite: Félix-Silva, A. V., \& Soares, G. P. (2021). Subjectivation processes in art and mental health in a judiciary asylum. Psicologia: Ciência e Profissão, 41 (n.spe 4), 1-16. https://doi.org/10.1590/1982-3703003212322

Cómo citar: Félix-Silva, A. V., \& Soares, G. P. (2021). Procesos de subjetivación en el arte y salud mental en un manicomio judicial. Psicologia: Ciência e Profissão, 41 (n.spe 4), 1-16. https://doi.org/10.1590/1982-3703003212322 